\title{
Association of low anti oxidant status with hypertension: cause or consequence
}

\author{
Dr. Rasmita Kumari Padhy ${ }^{1}$ Dr.Suvendu Sekhar Acharya ${ }^{2}$,Dr. Nirupama Devi ${ }^{3}$, \\ Dr. Roma Rattan ${ }^{4}$, Dr. Srikrushna Mahapatra ${ }^{5}$. \\ ${ }^{5}$ Professor and HOD, Department of Biochemistry, MKCG Medical College, Berhampur \\ ${ }^{1,3,4}$ Assistant Professor, Department of Biochemistry, MKCG Medical College, Berhampur \\ ${ }^{2}$ Assistant Professor, Department of Medicine, MKCG Medical College, Berhampur
}

\begin{abstract}
Background and objectives: Recent studies imply an increasing association of oxidative stress in the pathogenesis of hypertension. This study was designed to evaluate oxidative stress in hypertensive subjects and to assess the correlation of antioxidant status with the severity of hypertension.

Material and methods: Ninety-six hypertensive cases were divided into three groups based on severity of hypertension as per JNC VII classification. Lipid profile, antioxidant power of serum(FRAP assay) and oxidant load of serum(FOX2) of hypertensive cases were compared with an equal number of age and sex matched healthy normotensive controls. Data was analysed by Student's t test and Pearson's correlation.

Result: Lipid profile, oxidant load was significantly higher in hypertensive patients in comparison to controls $(P<0.001)$. Antioxidant status was lower in hypertensives as compared to controls. A significant correlation was observed between lipid profile vs. oxidative stress and hypertension vs. low antioxidant level $(r=0.835, P<0.001)$

Conclusion: Above findings demonstrate a strong association between blood pressure, dyslipidaemia and oxidative parameters shows a possible role of oxidative stress in the severity of hypertension.
\end{abstract}

Key words: hypertension, oxidative stress, antioxidant load

\section{Introduction}

Hypertension is one of the leading causes of global burden of disease. 7.6 million Deaths (13-15\% of the total) and 92 million disability adjusted life worldwide were attributable to high blood pressure in $2001 .{ }^{1}$

Hypertension prevalence is $33.5 \%$ in non-Hispanic blacks, $28.9 \%$ in whites seen in America. In India the prevalence rate is 59.9 and 69.9 per thousand males and females respectively in the urban and 35.5 and 35.9 per thousand males and females respectively in rural population. The likelihood of hypertension increases with age and among individuals age $>60$ the prevalence is $65.4 \% .^{2}$

There is no natural dividing line between high and normal blood pressure as it is a continuous variable. There have been multiple proposed cut off points for the definition of high blood pressure. According to the JNC-VII criteria (Joint National Committee), systolic pressure equal or more than $140 \mathrm{~mm} \mathrm{Hg}$ and or a diastolic pressure equal to or greater than $90 \mathrm{mmHg}$ is taken as the diagnostic criteria of hypertension. ${ }^{2}$ The classification is given in table1.

Numerous studies have implied the association of hypertension with vascular oxidative stress. Potentially harmful reactive oxygen species (ROS) are constantly produced during normal aerobic metabolism and they are safely removed by a variety of biological antioxidants. They are involved in maintaining cellular and physiological equilibrium such as regulation of vascular tone, sensing oxygen tension and endothelial dysfunction, but it is unknown whether this abnormality is a primary event or a consequence of increased blood pressure. ${ }^{3}$ Antioxidant protection can operate at several different levels within cells by preventing radical formation, repairing oxidative damage caused by radicals, increasing the elimination of damaged molecules and apoptosis of excessively damaged tissue. When prooxidants increase or antioxidants fail, a situation of oxidative stress arises ${ }^{(3,4)}$

It is mentioned that oxidative stress inactivates endothelium derived nitric oxide, the most important endogenous vasodilator which promotes vasoconstriction. Due to damage of vascular smooth muscle cells and endothelial cells there is increased endothelial permeability and stimulation of inflammation. These changes may lead to altered endothelial cell eicosanoid metabolism, increases the intra cellular free calcium concentration. Oxidative stress promotes vascular smooth muscle cell proliferation, hypertrophy and collagen deposition so that there is narrowing of vascular lumen. Increased oxidative stress also impairs endothelial relaxation and increases vascular contractility.ROS induced vasoconstriction include oxidation of arachidonic acid and formation of vasoconstrictive eicosanoids (prostaglandin $\mathrm{F}_{2 \alpha}$ ) it also inhibits the synthesis of vasodilator PGI. ${ }^{7}$ ROS can activate signaling cascades in vascular smooth muscle cells that induce remodeling in resistance arteries, 
resulting in increasing wall rigidity and narrowing of the lumen. This changes have been assumed to cause and progression of blood pressure. Some studies have reported that antioxidant therapy have improved vascular function and reduced blood pressure in experimental animal models and humans. Nevertheless, the available data is inconclusive and the relationship between blood pressure and oxidative stress in humans needs to be elucidated. ${ }^{8,9}$

Hence, this study was designed to (a) compare oxidative stress in hypertensive and normotensive subjects; (b) to find a correlation between low antioxidant status with the severity of hypertension.

\section{Material and methods}

This case-control study included 96 hypertensive patients (male-60, female-36) attending medicine outpatient department of M.K.C.G. Medical College and Hospital. An equal number of age and sex matched healthy controls were included. The study was approved institutional ethics committee.

The hypertensive patients fulfilling the following criteria like newly diagnosed, age 50-65 years, without any associated systemic diseases such as diabetes mellitus, cardiovascular, renal and hepatic diseases were included in this study. None of the hypertensive patients had history of smoking or alcohol. The physiological parameters such as age, height, weight, blood pressure and duration of disease at the time of admission were noted.

\section{Measurement of blood pressure (15)}

Each subject was seated in a quiet and comfortable position for five minutes, with feet on the floor and arm supported at heart level and then two readings of BP were measured on the right arm, five minutes apart with a mercury sphygmomanometer (cuff size 12.5 X $40 \mathrm{~cm}$ ) with auscultator method of BP measurement. BP readings were confirmed in the contra lateral arm at the same time. The SBP and DBP were read to the nearest $2 \mathrm{~mm} \mathrm{Hg}$. First and fifth phases of Korotkoff's sounds were taken as criteria for SBP and DBP respectively. The average of the two consecutive readings was recorded.

All the biochemical parameters were estimated in the Regional diagnostic centre of the department of Biochemistry, M.K.C.G Medical College and hospital. Fasting venous blood was collected and was immediately assayed. Blood sugar, total cholesterol, Triglyceride (TG), HDLcho ( high density lipoprotein cholesterol), LDLcho (low density lipoprotein cholesterol) were estimated using commercial kits adapted to EM360 Erba Transasia auto analyser. All the kits were purchased from Erba diagnostics, Mannheim, Germany.

Oxidative stress was measured by oxidation products in xylenol orange version 2 (FOX2 assay) ${ }^{10}$. The FOX2 reagent comprises two stock solutions, A and B. stock solution A was prepared by dissolving ammonium ferrous sulphate in sulphuric acid. Subsequently Xylenol orange was added to the above solution. Solution B was prepared by dissolving BHT (Butylated Hydroxy Toluene) in methanol. Total oxidant stress was measured as equivalent of $\mathrm{H}_{2} \mathrm{O}_{2}$ in $\mu \mathrm{mol} / \mathrm{L}$. Antioxidant power of serum was measured by Ferric Reducing Ability of Plasma capacity (FRAP assay). For FRAP assay reagents includes acetate buffer, TPTZ (2,4,6-tripyridyl-striazine). ${ }^{11}$ Total antioxidant power was expressed as equivalent of Ferrous sulphate in $\mu \mathrm{mol} / \mathrm{L}$.

Statistical Analysis

Data is expressed as mean \pm standard deviation (SD). The data was analysed by students $t$ test for unpaired data. Correlation was derived by Pearson's correlation analysis. A p value $<0.05$ was considered significant. Statistical analysis was done using SPSS version 16 software.

\section{Results}

Table I shows the classification of hypertension,which is classified into prehypertension and hypertension. Demographic profile of the study subjects is depicted in Table 2 it included 60 males and 36 females with the male-to-female ratio of 1.66 and controls consisted of 55 male and 41 females with a male-tofemale ratio of 1.42 Cases had a mean age of $58 \pm 8.2$ years compared to the mean age $58 \pm 8.6$ years of controls . Duration of hypertension was $4.5 \pm 1.2$ years. SBP of hypertensive cases $164.5 \pm 13.6 \mathrm{~mm} \mathrm{Hg}$ and DBP $99.06 \pm$ 11.9 as compared to controls with SBP $118.7 \pm 4.87 \mathrm{~mm} \mathrm{Hg}$ and DBP $82.34 \pm 3.5 \mathrm{~mm} \mathrm{Hg}$. There was no significant difference between the BMI of cases (24.3 \pm 4.2$)$ and that of controls (24.06 \pm 3.7$)$.

Clinical and laboratory data as represented in Table 3. Significant difference was not observed between the blood glucose of cases $(107 \pm 6.4 \mathrm{mg} / \mathrm{dl})$ and that of controls $(101 \pm 8.6)$. There was significant ( $\mathrm{p}$ value 0.001$)$ difference in the lipid profile between cases (total cholesterol-201.14 $\pm 6.12 \mathrm{mg} / \mathrm{dl}$; triglyceride- $159.18 \pm 11.7$ $\mathrm{mg} / \mathrm{dl}$; HDL cholesterol-31.08 $\pm 3.59 \mathrm{mg} / \mathrm{dl} ;$ LDL cholesterol-182.03 $\pm 14.86 \mathrm{mg} / \mathrm{dl}$ ) and controls (total cholesterol-147.41 $\pm 1.74 \mathrm{mg} / \mathrm{dl}$; triglyceride- $89.40 \pm 22.2 \mathrm{mg} / \mathrm{dl} ; \quad$ HDL cholesterol-36.07 $\pm 6.91 \quad \mathrm{mg} / \mathrm{dl}$; LDLcholesterol-132.03 $\pm 18.07 \mathrm{mg} / \mathrm{dl})$.

Figure 1 shows the relationship between oxidant load (FOX2) and total antioxidant capacity (FRAP). When the FOX2 label increases the FRAP level falls.

Table 4 and Figure 2 shows there is a significant increase in the oxidant load and a significant decrease in the total antioxidant power of the serum of hypertensive patients as compared to the normotensive controls. The 
serum oxidant load measured by FOX2 assay of cases is $12.4 \pm 1.6 \mu \mathrm{mol} / \mathrm{L}$ (equivalent of $\mathrm{H}_{2} \mathrm{O}_{2}$ ) and that of controls is $4.33 \pm 1.7 \mu \mathrm{mol} / \mathrm{L}$ (equivalent of $\mathrm{H}_{2} \mathrm{O}_{2}$ ) with $\mathrm{p}$ value 0.001 . The serum total antioxidant level was observed to decrease with an increasing severity of hypertension. The total serum antioxidant (FRAP) of the cases is $61.37 \pm 4.71 \mu \mathrm{mol} / \mathrm{L}$ (equivalent of Ferrous Sulphate) and that of the controls is $423 \pm 15.23 \mu \mathrm{mol} / \mathrm{L}$ (equivalent of Ferrous Sulphate). Pearson's correlation revealed a significant negative correlation between oxidant load and antioxidant status with $\mathrm{R}^{2}=-0.797$ and $\mathrm{p}$ value $=0.000$.

Table 5 depict the correlation between the oxidative stress parameters and age, BMI, SBP, DBP and lipid profile. Significant positive correlation was observed between lipid profile, increased systolic and diastolic blood pressure and oxidant load (FOX2). Significant negative correlation was observed between lipid profiles, increased systolic and diastolic blood pressure and antioxidant capacity (FRAP).

\section{Discussion}

Hypertension is a complex multifactorial disease. hypertension is characterized by an increase in systolic and/or diastolic blood pressure (SBP and DBP) than the upper limit of the optimal level as per the JNC VII guidelines. In the present study, both the SBP and DBP of all the cases were significantly higher than that of controls. ${ }^{12}$ Confounding factors which might influence the study parameters were minimized since all the participants were drawn from the same population. Almost all the study participants had similar diet, lifestyle and daily exercise habit patterns.

The findings of the present study demonstrate a strong association between blood pressure and oxidative stress parameters. The increased oxidative stress parameter levels observed in the hypertensive cases of our study is consistent with the findings of several previous studies ${ }^{(13-15)}$. However, our study findings are not in agreement with certain other studies, where no significant association was found. ${ }^{(16-18)}$. Russo et al showed that essential hypertension is associated with greater lipoperoxidation than normal and an imbalance in antioxidant status suggesting oxidative stress is important in the pathogenesis of essential hypertension. ${ }^{19}$ The correlation of blood pressure with oxidative stress parameters in hypertensive subjects suggests that these parameters have a blood pressure modulating effect ${ }^{(20-21)}$. In our study hypertensive cases showed an impaired total antioxidant status, which is in agreement with the previous studies ${ }^{(22-24)}$. Further, the negative correlation between SBP and DBP with total antioxidant status assed by FRAP levels suggests the importance of serum antioxidant status in blood pressure modulation. In normotensives subjects there was no significant positive correlation between blood pressure and antioxidant status. Many recent studies have documented that exposure to ROS increase the

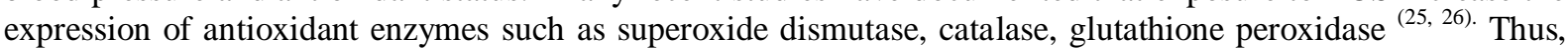
genes encoding these enzymes are co-ordinately regulated by antioxidant responsive elements (ARE) in their regulatory regions, a process which occurs through the activation of transcription factor NF-E2-related factor 2 (Nrf2) (27). The binding of Nrf2 to AREregions in genes causes up-regulation of the downstream genes which regulate the antioxidant activity of enzymes in response to ROS activity. It may be noted that this mechanism is triggered in most patients of hypertension. in response to their increased oxidant load as compared to normotensives. The significant negative correlation between SBP vs FRAP and DBP vs FRAP in hypertensive cases in our study strongly indicates the low antioxidant status of the patients. A significant positive correlation between SBP and DBP vs FOX2 value shows the increased oxidative stress in patients of hypertension.

Table 3 shows a significant difference in lipid parameters of the hypertensive cases as compared to controls. Triglycerides, Total cholesterol, LDL cholesterol are high and HDL cholesterol is low in hypertensive cases as compared to controls. Dyslipidaemia causes a prolonged increase in lipid per oxidation. This is due to generation of reactive oxygen species by leukocytes and p47 phox protein along with the activation of nuclear factor KB and inflammation. ${ }^{28}$ Further more we measured the FRAP and FOX2 level in different stages of hypertension. Table 4 shows the FRAP level declines as the severity of hypertension increases, there is a significant difference $(\mathrm{p}<0.001)$ found between prehypertension and stage II hypertension. Similarly the FOX2 level increases accordingly with increasing severity ( $\mathrm{p}<0.001)$. In table $2 \& 4$ we found that there is no significant difference between age, BMI and oxidative stress parameters. Irrespective of age and BMI dyslipidaemia has a strong relationship with FRAP and FOX2 assay.

The high oxidative stress in hypertensive patients may be due to their decreased antioxidant activity and/or an increased oxidant load. This derangement leads to damage to various biomolecules in hypertensive patients ${ }^{29}$. As a consequence, increased oxidant load leads to reduction in endothelium- dependant vasodilatation of vascular smooth muscles in hypertensive patients ${ }^{(30-32) .}$ This increase in blood pressure contributes to an increase in ROS and oxidant load, thereby enhancing the ROS mediated hypertension through a complex interdependent cycle.

\section{Conclusion}

From our study it is clear that increase in oxidative stress is associated with hypertension. It is not clear whether the reactive oxygen species initiate the development of hypertension or are due to the vascular damage observed in hypertension. From the above data in our study it is concluded that oxidative stress increases 
according to the severity of hypertension. As it is not clearly established whether the oxidative stress is the cause or the effect of the hypertension, the potential value of antioxidant supplements in diet to reduce blood pressure via the reductions in oxidative stress should be further evaluated.

\section{References:}

[1] Park K. Hypertension. In Park's textbook of preventive and social medicine $20^{\text {th }}$ edition Park K. Jabalpur: M/S Banarasidas Bhanot 2009; 323-327.

[2] Harrison's principles of Internal Medicine $18^{\text {th }}$ edition volume 2 ;2042-2048

[3] Rodrigo R, Passalacqua W, Araya J, Orellana M, Rivera G:Implications of oxidative stress and homocysteine in the pathophysiology of essential hypertension. J Cardiovasc Pharmacol 2003; 42: 453-461.

[4] Miyajima K, Minatoguchi S, Ito Y, et al: Reduction of QTc dispersion by the angiotensin II receptor blocker valsartan may be related to its anti-oxidative stress effect in patients with hypertension. Hypertens Res 2007; 30: 307-316.

[5] Pedro-Botet J, Covas MI, Martin S, Rubies-Prat J: Decreased endogenous antioxidant enzymatic status in essential hypertension. J Hum Hypertens 2000; 14: 343-345

[6] Lassègue B, Griendling K: Reactive oxygen species in hypertension. An update. Am J Hypertens 2004; 17: 852-860.

[7] Touyz RM, Schiffrin EL: Reactive oxygen species in vascular biology: implications in hypertension. Histochem Cell Biol 2004; 122: 339-352.

[8] Dusting GJ, Akita K, Hickey H, Smith M, Gurevich V: Cyclosporin A and tacrolimus (FK506) suppress expression of inducible nitric oxide synthase in vitro by different mechanisms. Br J Pharmacol 1999; 128: 337-344.

[9] Zicha J, Dobesova Z, Kunes J: Relative deficiency of nitric oxide-dependent vasodilation in salt-hypertensive Dahl rats: the possible role of superoxide anions. J Hypertens 2001; 19: 247-254.

[10] Iris F.F. Benzie and J.J.The Ferrc Reducing ability of plasma (FRAP) as a Measure of "Antioxidant Power"; the FRAP assay. Strain analytical Biochemistry 239. 70-76 (1996) no.0292

[11] Visnja Katalinie, IIza Salamunic, Senijo Pazanin, Rosanda Mulic, Marjia Milisic and Darko Ropae:The Antioxydant Power and level of Lipid Peroxydation Products in the sera of apparently healthy adult males.coll Antropol 31 (2001) 1:165-171.

[12] Ghiadoni L,Magagna A,Versari D,Kardasz I,Huang Y:Different effect of antihypertensive drugs on conduit artery endothelial function. Hypertension 41:1281-1286,2003.

[13] Cracowski JL, Baguet JP, Ormezzano O, et al. Lipid peroxidation is not increased in patients with untreated mild-to-moderate hypertension. Hypertension 2003; 41: 286-288.

[14] Ward NC, Hodgson JM, Puddey IB, Mori TA, Beilin LJ, Croft KD. Oxidative stress in human hypertension: association with antihypertensive treatment, gender, nutrition and lifestyle. Free Radic Biol Med 2004;36: 226-232.

[15] Sugiyama M, Ohashi M, Takase H, Sato K, Ueda R, Dohi Y. Effects of atrovastatin on inflammation and oxidative stress. Heart Vessels 2005;20: 133-136

[16] Moreno MU, Jose GS, Fortuno A, Beloqui O, Diez J, Zalba G: The C242T CYBA polymorphism of NADPH oxidase is associated with essential hypertension. J Hypertens 2006;24: 1299-1306.

[17] Kashyap MK, Yadav V, Sherawat BS, et al: Different antioxidants status, total antioxidant power and free radicals in essential hypertension. Mol Cell Biochem 2005; 277: 89-99.

[18] Muda P, Kampus P, Zilmer M, et al: Effect of antihypertensive treatment with candesartan or amlodipine on glutathione and its redox status, homocysteine and vitamin concentrations in patients with essential hypertension. J Hypertens 2005; 23 : 105-112.

[19] Russo C, Olivieri O, Girelli D, et al: Anti-oxidant status and lipid peroxidation in patients with essential hypertension. J Hypertens 1998; 16: 1267-1271.

[20] Talalay P, Dinkova-Kostova AT, Holtzclaw WD: Importance of phase 2 gene regulation in protection against electrophile and reactive oxygen toxicity and carcinogenesis. Adv Enzyme Regul 2003; 43: 121-134.

[21] 22. Bae I, Fan S, Meng Q, et al: BRCA1 induces antioxidant gene expression and resistance to oxidative stress. Cancer Res 2004; 64: 7893-7909.

[22] Lee JM, Johnson JA: An important role of Nrf2-ARE pathway in the cellular defense mechanism. J Biochem Mol Biol2004; 37: 139-143.

[23] Lassègue B, Griendling K: Reactive oxygen species in hypertension. An update. Am J Hypertens 2004; 17: 852-860.

[24] Touyz RM, Schiffrin EL: Reactive oxygen species in vascular biology: implications in hypertension. Histochem Cell Biol 2004; 122: 339-352.

[25] Fliser D, Buchholz K, Haller H; European Trial on Olmesartan and Pravastatin in Inflammation and Atherosclerosis (EUTOPIA) Investigators. Antiinflammatory effects of angiotensin II subtype 1 receptor blockade in hypertensive patients with microinflammation. Circulation 2004;110:1103-1107.

[26] Dohi Y, Ohashi M, Sugiyama M, Takase H, Sato K, Ueda R. Candesartan reduces oxidative stress and inflammation in patients with essential hypertension. Hypertens Res. 2003;26: 691- 697

[27] Clerk A, Fuller SJ, Michael A, and Sugden PH. Stimulation of "stress-activated" mitogen-activated protein kinases/c-Jun Nterminal kinases, and p38 mitogen-activated protein kinases in perfuse rat hearts by oxidative and other stresses. $\mathrm{J}$ Biol Chem1998;273: 7228-7234.

[28] Clerk A, Michael A, and Sugden PH. Stimulation of multiple mitogenactivated kinase subfamilies by oxaditave stress and phosphorilation of the small heat shock protein, HSP 25/27, in neonatal ventricular myocytes. J Biochem 1998; 333: $581-583$.

[29] Mervaala E, Finckenberg P, Lapatto R, Muller DN, Park JK, Dechend R, Ganten D, Vapaatalo H, and Luft FC. Lipoic acid supplementation prevents angiotensin II-induced renal injury. Kidney Int 2003;64: 501-508.

[30] Mu“ ller DN, Dechend R, Mervaala EM, Park JK, Schimidt F, Fiebeler A, Theuer J, Breu V, Ganten D, Haller H, and Luft FC. NF_B inhibition ameliorates angiotensin II-induced inflammatory damage in rats. Hypertension 2000; 35: $193-201$.

[31] Yogesh R.Pawade,Suresh S. Ghangale,Abhay N. Nagdeote. Urinary Albumin Excretion Rate:Diagnostic and prognostic Utility in Essential Hypertension. Indian Medical Gazette:March 2012. 
Association of low anti oxidant status with hypertension: cause or consequence

Table 1 : classification of hypertension.

\begin{tabular}{|l|l|l|}
\hline & Systolic $(\mathrm{mmHg})$ & Diastolic $(\mathrm{mmHg})$ \\
\hline Normal & $<120$ & $<80$ \\
\hline prehypertension & $120-139$ & $80-89$ \\
\hline Stage1 & $140-159$ & $90-99$ \\
\hline Stage2 & $\geq 160$ & $\geq 100$ \\
\hline
\end{tabular}

According to the JNC VII hypertension is classified as prehypertension, stage 1 and stage 2 as per the above table.

Table2: Baseline demographic profile of hypertensive cases and normotensive controls

\begin{tabular}{|l|l|l|}
\hline Pt profile & Hypertensive cases & Controls \\
\hline Number & 96 & 98 \\
\hline Age (in years) & $58.4 \pm 8.2$ & $58.4 \pm 8.6$ \\
\hline Sex(M/F) & $60 / 36$ & $55 / 41$ \\
\hline Duration of hypertension & $4.5 \pm 3.8$ & Normotensive \\
\hline BMI $\left(\mathrm{Kg} / \mathrm{m}^{2}\right)$ & $22.96 \pm 4.2$ & $22.06 \pm 3.7$ \\
\hline Systolic BP(mm Hg) & $164.5 \pm 13.6$ & $118.7 \pm 4.87$ \\
\hline Diastolic BP(mmHg) & $99.06 \pm 11.9$ & $82.34 \pm 3.5$ \\
\hline
\end{tabular}

Baseline demographic data was recorded at the time of admission.

Table3

Comparison of Clinical and Biochemical parameters of hypertensive patients and normotensive controls

\begin{tabular}{|l|l|l|l|}
\hline Parameters & hypertensive's & Controls & P value \\
\hline $\mathrm{SBP}(\mathrm{mmHg})$ & $164.5 \pm 13.6$ & $118.7 \pm 4.87$ & 0.05 \\
\hline DBP $(\mathrm{mmHg})$ & $99.06 \pm 11.9$ & $82.34 \pm 3.5$ & 0.05 \\
\hline Blood sugar(mg/dl) & $107.8 \pm 6.4$ & $101 \pm 8.6$ & 0.542 \\
\hline Total cholesterol(mg/dl) & $201.14 \pm 62.12$ & $147.41 \pm 17.47$ & 0.001 \\
\hline Triglycerides(mg/dl) & $159.18 \pm 11.72$ & $89.40 \pm 22.2$ & 0.000 \\
\hline $\mathrm{HDL}-$ Cholesterol $(\mathrm{mg} / \mathrm{dl})$ & $31.08 \pm 3.59$ & $36.07 \pm 6.96$ & 0.015 \\
\hline LDL- Cholesterol $(\mathrm{mg} / \mathrm{dl})$ & $182.03 \pm 14.86$ & $132 \pm 18.07$ & 0.005 \\
\hline $\begin{array}{l}\text { FRAP }(\mu \mathrm{mol} / \mathrm{l}) \text { equivalent of Ferrous } \\
\text { Sulphate }\end{array}$ & $61.37 \pm 4.71$ & $423 \pm 15.23$ & 0.000 \\
\hline FOX2 $(\mu \mathrm{mol} / \mathrm{l})$ equivalent of $\mathrm{H}_{2} \mathrm{O}_{2}$ & $12.4 \pm 1.6$ & $4.33 \pm 1.7$ & 0.000 \\
\hline
\end{tabular}

Data is represented as mean \pm SD. Statistical significance is derived by unpaired student's $t$ test. A p value of $<$ 0.05 was considered significant.

Table 4: Comparision of oxidative stress parameters in different stages of hyperten

\begin{tabular}{|l|l|l|l|}
\hline Parameters & Pre hypertension & Stage I & Stage II \\
\hline FRAP $(\mu \mathrm{mol} / \mathrm{L})$ & $198.78 \pm 31.82^{*}$ & $169.87 \pm 40.84^{* *}$ & $61.37 \pm 4.71^{* * *, a, c}$ \\
\hline FOX2 $(\mu \mathrm{mol} / \mathrm{L})$ & $6.02 \pm 4.9^{\dagger}$ & $6.83 \pm 5.1^{\dagger \dagger, \mathrm{b}}$ & $12.4 \pm 1.6^{\dagger \dagger, \mathrm{d}}$ \\
\hline
\end{tabular}

Data represented as mean \pm SD. Statistical analysis was done by one-way ANOVA and post hoc test Tuckey HSD. $*$ p value $<0.05$ as compared to controls $* *$ p value $<0.05$ as compared to stage II. *** p value $<0.05$ as compared to controls. $\mathrm{a}=\mathrm{p}$ value $<0.001$ as compared to

to Stage II; $\mathrm{c}=\mathrm{p}$ value $<0.001$ as compared to prehypertensive.

$\dagger \mathrm{p}$ value $<0.05$ as compared to controls; $\uparrow \dagger \mathrm{p}$ value $<0.05$ as compared to controls; $\dagger \dagger \uparrow \mathrm{p}$ value $<0.001$ as compared to controls; $\mathrm{b}=\mathrm{p}$ value $<0.001$ as compared to Stage III; $\mathrm{d}=\mathrm{p}$ value $<0.001$ as compared to prehypertensive.

Table 5: Correlation of oxidative stress parameters with age, BMI, SBP and DBP in hypertensive cases and normotensive controls.

\begin{tabular}{|c|c|c|c|c|}
\hline & \multicolumn{2}{|c|}{$\begin{array}{l}\mathrm{FOX} 2(\mu \mathrm{mol} / \mathrm{L}) \text { equivalent of } \\
\mathrm{H}_{2} \mathrm{O}_{2}\end{array}$} & \multicolumn{2}{|c|}{$\begin{array}{l}\text { FRAP }(\mu \mathrm{mol} / \mathrm{L}) \text { equivalent of } \\
\text { Ferrous Sulphate }\end{array}$} \\
\hline & r value & $\mathrm{P}$ value & r value & $\mathrm{P}$ value \\
\hline Age & 0.188 & 0.136 & 0.060 & 0.639 \\
\hline BMI & 0.177 & 0.162 & 0.219 & 0.082 \\
\hline SBP & 0.666 & 0.000 & -0.873 & 0.000 \\
\hline DBP & 0.627 & 0.000 & -0.681 & 0.000 \\
\hline Total & 0.234 & $<0.05$ & -0.464 & 0.000 \\
\hline
\end{tabular}




\begin{tabular}{|l|l|l|l|l|}
\hline cholesterol & & & \\
\hline TG & 0.300 & 0.01 & -0.479 & 0.000 \\
\hline
\end{tabular}

Significant positive correlation was observed between lipid profile, increased systolic and diastolic blood pressure and oxidant load (FOX2). Significant negative correlation was observed between lipid profiles, increased systolic and diastolic blood pressure and antioxidant capacity (FRAP).

Figure 1 shows the correlation of the total antioxidant defense load(FRAP) and oxidative stress level(FOX2).

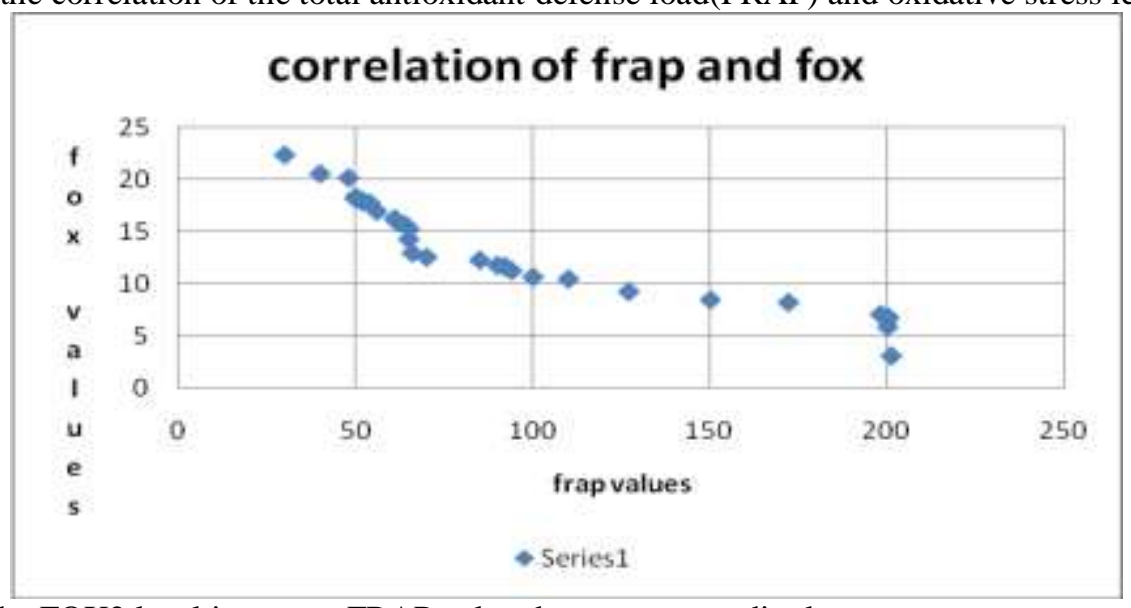

It shows when the FOX2 level increases FRAP value decreases accordingly.

Figure2 showing correlation of FRAP and FOX2 with blood pressure

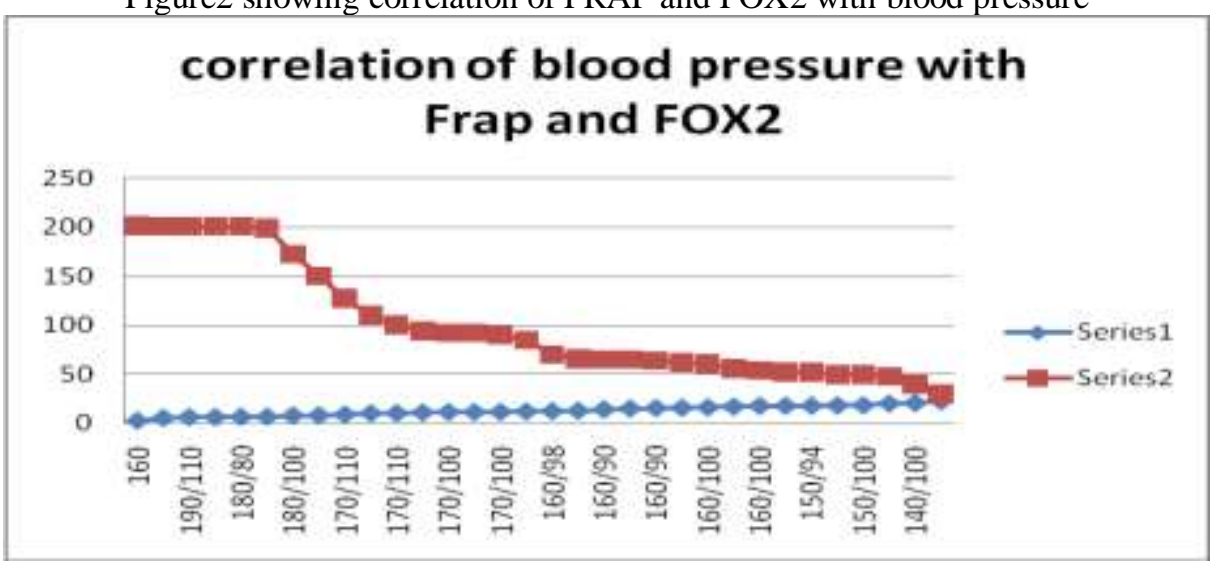

Series 1 depicts FOX2 levels and Series 2 shows FRAP levels. Significant positive correlation was observed between increased blood pressure and FOX2 levels (total oxidant load) and significant negative correlation was found between blood pressure and FRAP levels (total antioxidant status).

\section{AUTHORS DECLARATION AND COPYRIGHT FORM}

The manuscript entitled: "Association of low antioxidant status with hypertension: cause or consequence" has not been sent for publication for any other journal and will not be done so before hearing about the decision of the editorial board of this journal. The author(s) declare(s) that this is the original work done by me. The author warrants that the article contains no libellous or unlawful statements and does not infringe on the right of the others. 